\title{
Paragraphs or Lists? The Effects of Text Structure on Web Sites
}

Joyce Karreman

University of Twente

J.Karreman@utwente.nl

\author{
Nicole Loorbach \\ University of Twente \\ N.R.Loorbach@utwente.nl
}

\begin{abstract}
This paper describes a study that we conducted to investigate the effects of the visual text structure on Web sites on the users' browsing behavior and on their appreciation for the Web site. It has been known for a long time that the visual structure of a text has considerable effects on reading behavior, but surprisingly little research has been done to define guidelines for the structure of texts on Web sites. We compared two versions of a Web site, one version contained text structured using paragraphs, the other version contained mainly text structured as numbered lists. Over 300 participants browsed one version of the site, and answered a survey about the content of the Web site and about their appreciation for the site. The results show that participants who used a Web site with text structured as lists performed better than participants who used a Web site with text structured using paragraphs: they visited more Web pages and they appreciated the site better.

Key words: text structure, document design, web site design.
\end{abstract}

\section{Introduction}

It has been known for a long time that the visual structure of a text has considerable effects on the reading behavior, the comprehension of a text, and the memory for this text. Text signaling devices like, for example, headings, previews and typographical cues that emphasize aspects of the text' content or structure have in general positive effects on the reading process (see for a research overview [1]).

A frequently used way to structure a text is a listwise presentation of the text. Especially in procedural texts like manuals, lists are extensively used. One reason for the use of lists of actions is that a listwise presentation aids the users who perform the described actions immediately, while consulting the text (for example, [2]). In other words, lists of actions support the process of switching between text and task. However, lists are not only used in procedural texts that describe actions that can be performed immediately. Enumerations and bulleted lists are found in a variety of text types, but surprisingly little research has been done into the effects of a listwise presentation of texts. Moreover, the results of these studies are contradictory.

Lorch and Chen showed that numbering sentences in a narrative text directed attention to these sentences, and these sentences were better memorized than unsignaled sentences [3]. However, the participants in this study read a narrative text, in which the use of numbers seemed to be somewhat unnatural. This might be the reason that the added numbers attracted the readers' attention.

Diehl and Mills conducted a study in which they investigated the effects of listwise instructions compared to instructions that were structured using paragraphs [4]. Their results showed that listwise instructions led to better task performance but that instructions structured using paragraphs led to better memory for the text.

Geiger and Millis showed that a procedural text that consisted of paragraphs led to better comprehension of the text than a text that consisted of listwise structured actions, if the participants were asked to keep in mind that they had to perform the tasks later [5]. So, these studies show, unexpectedly, relatively negative effects of using lists.

In these former studies, the effects of the structure of print text are investigated. Nowadays, more and more texts are read from a computer screen. Relatively little research has been done into the effects of the structure of texts that are read from a screen, but it is known that the process of reading from a screen differs from the process of reading from paper (for example, [6]). It is, therefore, not possible to generalize the research results from studies about reading on paper directly to reading on screen (see also, [7]). More research is needed to define guidelines for texts that are read from a screen, such as text on Web sites [6], [8].

In this paper, we describe a study that is conducted to answer this research question: What effects has a Web site's text structure (listwise versus paragraphs) on the users' knowledge about the content of the text, on their 
browsing behavior and on their appreciation for the Web site?

The study was conducted in a real life environment where participants could use their own computers at a time and place of their choice. We decided to conduct the study in a real life environment and not in a laboratory to increase the external validity of our study (see also [8])

We measured the effects of the text structure on the users' knowledge of the Web site's content by asking them a number of questions after they browsed the site. The effects on the appreciation for the Web site were measured in different ways. First, the users' appreciation was measured directly by asking them to answer some questions about their appreciation of the site. Second, their level of appreciation is measured indirectly by analyzing their browsing behavior. The time that the users spent on browsing the site and the number of pages that they visited was measured. Because the users were browsed the Web site in a natural environment and because they were told that they could stop browsing when they wanted, spending more time or visiting more pages would indicate that the users appreciated the Web site.

As far as known, there is no research with regard to the use of listwise structured text on Web sites. The common belief is that using signals, such as lists, is favorable for users of Web sites because they like to be able to scan the text quickly. Signals help them to do that [9]. It has also been shown that poor structural cues affect readers of online text more negatively than readers of print text [7]. Therefore, it can be expected that a listwise structure has more favorable effects than a text structured using paragraphs. However, no sound arguments for this expectation are found in the literature until now.

\section{Method}

\section{Participants}

Students of the University of Washington ${ }^{1}$ participated in this study for course credit. We disqualified a number of participants from the study because they only visited the main page of the Web site, and did not browse through the site. Some others were disqualified because their data were not logged appropriately. A total of 347 participants were retained for data analysis. Their mean age was 21.4 years.

\footnotetext{
${ }^{1}$ We would like to thank the department of Technical Communication for their hospitality. In particular, we would like to thank Jan Spyridakis. Thanks to Edward Galore for his generous assistance with the preparation of our study.
}

\section{Web site}

Several versions of a Web site about studying at the University of Twente in Enschede, the Netherlands, were created $^{2}$. This Web site was aimed at students from all over the world. The Web site contained information about the different things a student needs to do directly before and upon arrival in the Netherlands, such as how to travel from the airport to the university, how to register at the university and how to open a bank account. The Web site consisted of 20 pages: one home page, five pages with general information about a certain topic (official documents and transportation, for example) and 14 pages with more detailed information about what a students needs to do upon arrival in the Netherlands.

Half of the versions of the Web site contained only paragraph structured information (P-Web site). The actions that had to be undertaken when going to study in the Netherlands were also described using paragraphs. The other half of the versions contained also some information structured as paragraphs, but all described actions were structured as numbered lists (L-Web site). Example pages from both the L-Web site and the P-Web site are shown in figures 1 and 2 . Apart from the text structure, the versions of the Web site were exactly the same: the lay out of the versions was the same, even as the content of the information. We used the same wording of the sentences in each version, but we added adverbs and conjunctions like next and and to the text on the PWeb site, when necessary.

We used the software package WebLabUX, that was designed for conducting remote, internet-based experiments on Web design, for measuring participants' behavior and performance on the Web site [10]. This toolkit assigned participants to one of the versions of the Web site. Their navigational behavior was tracked, so we could determine which pages were visited, for how long, in which order, and which link was clicked to arrive at each page.

\section{Survey}

To measure participants' memory for the content of the Web site, we constructed a survey that consisted of 19 multiple choice questions. The correct answer on each question was stated literally on the Web site. One of these questions was, for example: The university's Housing Office offers housing to all intemational students. What should you do to apply for housing in Ensche de?

\footnotetext{
${ }^{2}$ This study was part of a larger study, in which we also investigated the effects of some other variables. We constructed six different versions of the Web site. In this paper, we focus on the differences between the versions with paragraphs and the versions with lists.
} 


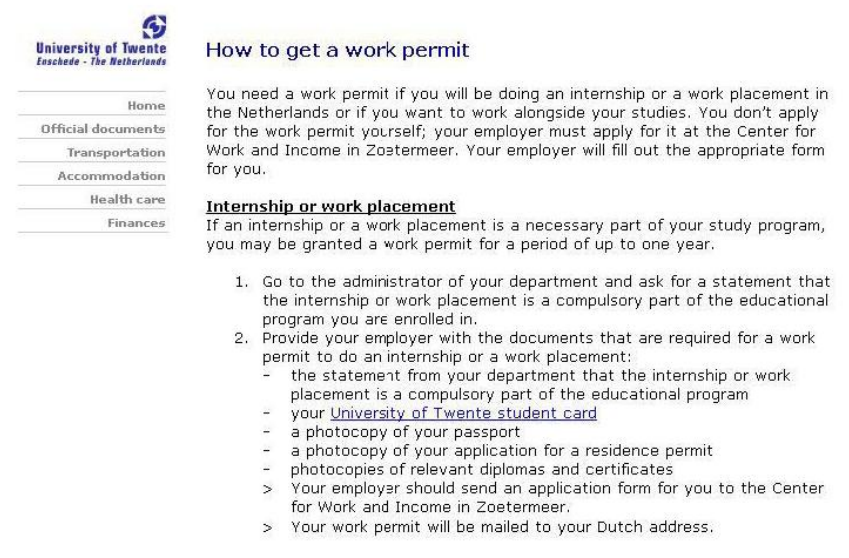

Figure 1. Example page from the L-Web site

Three other questions were formulated to measure the participants' appreciation for the Web site. These questions were: How interesting was the information you read?, How difficult was the information you read? and How enjoyable was the information you read? The participants had to answer these questions on a five point Likert scale, from very uninteresting / difficult / unenjoyable (1) to very interesting / easy / enjoyable (5).

\section{Procedure}

We invited the students to participate in our study by handing out a flyer with the URL of our study. When they entered the Web site, they had to read some introductory pages, including an informed consent statement. After that, they answered some questions about general demographic information. Then, they had to read a scenario; they were asked to imagine that they were planning to study in the Netherlands for some time and that they would depart very soon. They had to use the Web site to inform themselves about the things they had to do upon arrival, in order to go well-prepared to the Netherlands.

After having read the scenario, the participants were assigned to one of the versions of the Web site. They could stop using the Web site when they had the impression that they knew enough about the actions they would have to undertake in the near future. At that moment, they should click on the 'proceed to survey' button. Then, the participants had to answer a survey about their appreciation of the Web site and about their knowledge of the content. Finally, they were asked for general comments on the Web site. In total, the study took about 45 minutes on average.

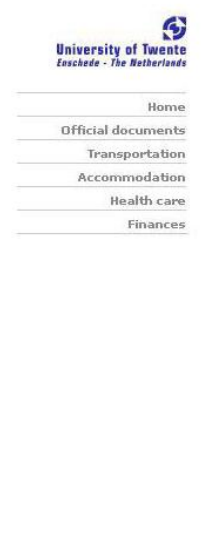

How to get a work permit

You need a work permit if you will be doing an internship or a work placement in the Netherlands or if you want to work alongside your studies. You don't apply for the work permit yourself; your employer must apply for it at the Center for
Work and Income in Zoetermeer. Your employer will fill out the appropriate form for you.

Internship or work placement If an internship or a work placement is a necessary part of your study program, for a period of up to one year.

Go to the administrator of your department and ask for a statement that the internship or work placement is a compulsory part of the educational program you are enrolled in. Then, provide your employer with the documents that are statement from your department that the internship or work placement is compulsory part of the educational program, your University of Twente studen card, a photocopy of your passport, a photocopy of your application for a residence permit, and photocopies of relevant diplomas and certificates. Your employer should send an application form for you to the Center for Work and
Income in Zoetermeer. Your work permit will be mailed to your Dutch address.

Figure 2. Example page from the P-Web site

\section{Results}

\section{Using the Web site}

The participants' data were statistically analyzed. Ttests were executed to test the differences between the results of the 169 participants who used the L-Web site and the 178 participants who used the P-Web site. The results regarding the participants' browsing behavior are summarized in table 1. This table shows that, in general, the participants who used the L-Web site performed better than the participants who used the P-Web site:

- The participants who used the L-Web site spent on average 1.5 minutes more on browsing the Web site than participants who used the P-Web site. A t-test showed, however, that this difference is not statistically significant $(\mathrm{t}=1.62 ; \mathrm{df}=345 ; \mathrm{p}=0.11)$.

- Participants who used the L-Web site visited on average more pages than the participants who used the $\mathrm{P}-\mathrm{Web}$ site. This difference is statistically significant $(\mathrm{t}$ $=2.65, \mathrm{df}=345 ; \mathrm{p}<0.01$ ).

- Participants who used the L-Web site answered on average more questions about the content of the Web site correctly than those who used the P-Web site. This difference is nearly statistically significant $(t=1.83$; df $=345 ; \mathrm{p}=0.07$ ).

- Participants who used the L-Web site appreciated the Web site better than participants who use the P-Web site. This difference is small, but highly statistically significant $(\mathrm{t}=2.85, \mathrm{df}=345 ; \mathrm{p}<0.01)$. 
Table 1. The effects of the text structure on the users' browsing behavior (means, standard deviations between brackets).

\begin{tabular}{|c|c|c|c|}
\hline & $\begin{array}{r}\text { L-site } \\
\mathrm{n}=169\end{array}$ & $\begin{array}{l}\mathrm{P} \text { - site } \\
\mathrm{n}=178\end{array}$ & $\begin{array}{c}\text { Total } \\
\mathrm{n}=347\end{array}$ \\
\hline $\begin{array}{l}\text { Total time on Web } \\
\text { site } \\
\text { (minutes: } \\
\text { seconds) }\end{array}$ & $\begin{array}{l}12: 40 \\
(9: 46)\end{array}$ & $\begin{array}{l}11: 06 \\
(8: 16)\end{array}$ & $\begin{array}{l}11: 52 \\
(9: 03)\end{array}$ \\
\hline $\begin{array}{c}\text { Number of visited } \\
\text { pages } \\
\text { (out of } 20 \text { ) }\end{array}$ & $\begin{array}{l}13.62 \\
(5.30)\end{array}$ & $\begin{array}{l}12.11 \\
(5.29)\end{array}$ & $\begin{array}{l}12.84^{\text {*2* }} \\
(5.34)\end{array}$ \\
\hline $\begin{array}{l}\text { Number of correctly } \\
\text { answered questions } \\
\text { (out of 19) }\end{array}$ & $\begin{array}{c}9.83 \\
(3.22)\end{array}$ & $\begin{array}{c}9.20 \\
(3.14)\end{array}$ & $\begin{array}{c}9.51 \\
(3.19)\end{array}$ \\
\hline $\begin{array}{l}\text { Appreciation for the } \\
\text { Web site } \\
\text { (five point scale) }\end{array}$ & $\begin{array}{c}3.27 \\
(0.62)\end{array}$ & $\begin{array}{c}3.07 \\
(0.69)\end{array}$ & $\begin{array}{l}3.17^{\text {**** }} \\
(0.67)\end{array}$ \\
\hline
\end{tabular}

$\mathrm{n}$ Number of participants who used the version of the Web site

* Mean score on the three questions about appreciation; Cronbach's alpha is 0.69

** $\quad \mathrm{p}<0.01$

\section{Participants' comments about the Web site's structure}

At the end of the study, we asked the participants for general comments on the Web site. They made positive as well as negative comments on a broad range of topics. Most remarks were about the lay out of the Web site. Quite a few participants considered the lay out to be boring:

- "I just thought the lay out of the Website was a little boring"

- "The site is pretty good, and would probably be useful to someone. There aren't a lot of interesting pictures, though, and that kind of makes it less interesting."

Because the study was focused on the text structure, we decided to use a simple lay out that should not distract the participants from the text. Therefore, these remarks are not surprising, but they highlight the importance of an attractive visual presentation of a Web site.

The participants also made a large number of remarks on the text structure. The comments of the users of the PWeb site were mainly negative. They did not like the paragraph structured text, and considered this text as difficult to read. Some participants suggested to organize the text listwise:
- "Some information could be presented in bullet points instead of paragraphs."

- "The information on the Website seemed useful and not too difficult. However, it was a little tedious to read. I think bullet points would make it easier to remember the important information."

- "The important things should stand out more, such as using bullets to list the documents required."

- "Instructions for multiple options (arriving by train, for instance) needed to be spread out in a bullet or numbered format so they can be distinguished better."

The participants who used the L-Web site made varying comments about the text structure. Some considered the distinction between the lists of actions and the other information types as not clear enough:

- "However in the pages themselves, the text layout was difficult to get interested in. For example, the "notes" and tips that were given melted into the text."

- "There was too much "fluff" on the Webpage, the instructional sections need to be more to the point and have the other comments later on in a different section."

For other participants, the distinction seemed to be clear:

- "I pretty much just read the bulleted points."

However, none of the participants commented negatively on the presence of numbered lists as such.

\section{Conclusion}

The results of this study are clear. For those types of Web sites, that consist of instructions that do not have to be performed immediately, a listwise presentation of the text is better than using paragraphs. The most salient result, however, is not that the participants who used the P-Web site have a slightly better memory for the content of the site than those who used the L-Web site, but that the appreciation for the L-Web site is significantly better than the appreciation of the P-Web site. Moreover, probably as a result of this, the participants who used the L-Web site were willing to browse the Web site more extensively than the participants who used the P-Web site. The first group visited significantly more pages than the second. The participants' comments on the Web site indicated that users prefer Web sites to be visually attractive. On top of that, they prefer text that is structured clearly, using signaling devices such as numbered lists.

The results indicate that the common beliefs about the use of text signaling devices are true, regarding the use of listwise presentation of text on Web sites. In particular, users appreciate lists better than paragraphs. These results are in contrast with the results of some studies that investigated the effect of the structure of print text [4], [5]. The results of this study illustrate that guidelines for structuring text print text can not be generalized directly 
to Web site texts. Future research into the effects of text signaling devices that emphasize the structure of a Web site text is needed.

\section{References}

[1] Lorch, R.F. Text-Signaling Devices and their Effects on Reading and Memory Processes. Educational Psychology Review. 1: 209-234, 1989.

[2] Boekelder, A., and M. Steehouder. Selecting and Switching: Some Advantages of Diagrams over Tables and Lists for Presenting Instructions. IEEE Transactions on Professional Communication. 41: 229 -241, 1998.

[3] Lorch, R.F., and A.H. Chen. Effects of Number Signals on Reading and Recall. Journal of Educational Psychology. 8: 263270,1986 .

[4] Diehl, V.A., and C. Mills. The Effects of Interaction with the Device Described by Procedural Text on Recall, True/False, and Task Performance. Memory \& Cognition. 23: 675-688, 1995.

[5] Geiger, J.F., and K.K. Millis. Assessing the Impact of Reading Goals and Text Structures on Comprehension. Reading Psychology. 25: 93-110, 2004.

[6] Spyridakis, J. Guidelines for Authoring Comprehensible Web Pages and Evaluating Their Success. Technical Communication. 47: 359-382, 2000.

[7] Bartell, A., L. Schultz, and J.H. Spyridakis. The Effect of Heading Frequency on Comprehension of Print versus Online Information. Technical Communication. 53: 416-426, 2006.

[8] Spyridakis, J.H., C. Wei, J. Barrick, E. Cuddihy, and B. Maust. Internet-Based Research: Providing a Foundation for Web Design Guidelines. IEEE Transactions on Professional Communication. 48: 242-260, 2005.

[9] Farkas, D. K., and J.B. Farkas. Principles of Web Design. Longman Publishers, 2002.

[10] Cuddihy, E., C. Wei, A.L. Bartell, J. Barrick, B. Maust, S.S. Leopold, and J.H. Spyridakis. Conducting Remote, Internet-based Experiments on Web Design. Proceedings of IEEE International Professional Communication Conference (July, Ireland), 554-561, 2005.

\section{About the Authors}

Joyce Karreman is affiliated with the Technical and Professional Communication Department at the University of Twente. Her research interests include user support and document design, in particular the use of different information types in instructive texts.

Nicole Loorbach is a $\mathrm{PhD}$ candidate in the Technical and Professional Communication Department at the University of Twente, the Netherlands. Her research interests include document design and technical communication, in particular motivational elements in technical documents. 